\title{
The effect of powder metallurgy process parameters on mechanical properties of micro and nano-iron powder
}

\author{
M. Delavari ${ }^{1}{ }^{*}$, A. Salarvand ${ }^{2}$, A. Rahi ${ }^{1}$, F. Shahri ${ }^{1}$ \\ ${ }^{1 *}$ Department of Mechanical Engineering, Iran University of Industries and Mines, IRAN \\ ${ }^{2}$ Department of Mechanical Engineering, Douroud Azad University, IRAN \\ Corresponding Authors: e-mail: Delavari.Mahdi@gmail.com
}

\begin{abstract}
The ever-increasing development of applying the iron pieces made by powder metallurgy in car industries and other usages depends on making pieces with high density and consequently acceptable physical and mechanical properties. Regarding the effect of decrease in the powder bits' size on improvement of the mechanical characteristics and on decrease in the temperature of sinter, the experiments on the pure iron powder with the bits' size of 5, 45, 63 micron in which $20 \%$ of iron nanopowder was added to the powder with the bits' size of 45 micron, have been studied. Mere iron nanopowder also was applied for experiments. Pieces are compacted under $300-850 \mathrm{MPa}$ and lubricants by 0.4 and 0.6 percent of the total weight was mixed with the powders. Various amounts of sintering time and sintering temperature were considered for the sintering of the samples. The survey suggested that applying micro powders resulted in an increase in the linear density and the strength at the relatively high temperatures and high keeping times. Sintering temperature and shrinkage has declined considerably with the decrease in the powder size and as a result the strength increases. High strength for products made by smaller powders under high pressures and low sintering temperatures using lubricated frame wall are obtained. SEM pictures from the fracture junctions of the samples show the decrease in porosity due to the close impact of the smaller powder size.
\end{abstract}

Keywords: sintering, mechanical properties, hardness, erosion resistance, compaction

DOI: http://dx.doi.org/10.4314/ijest.v3i9.7

\section{Introduction}

In the powder metallurgy process, the industrial pieces are produced through compacting powder in the frame and sintering within a controlled setting. As a natural character of powder metallurgy process a disadvantage is the production of a work piece with poor mechanical properties due to its porosity. High needed pressure and sintering temperature and long sintering period hinder the application of this process because of increasing process cost. The powder size, as an important parameter, has the potential to remove aforementioned drawbacks, as typically the temperature of sinter for the smaller powders goes down and also higher strengthened products are achieved using smaller powder sizes (Squire, 1947 and Park et al., 2004 and Gibbs-Thomson, 2003 and Fillabi et al., 2008). Sintering temperature, pressure, keeping time, powder density, and bits' size are the most important parameters on which the hardness of the produced piece is dependent on. The researches have shown that the effects of the parameters on the hardness are very intricate and their influence may change when the size of the particle decreases. The results suggest that in the sintering operation of the nanopowder of the tungsten alloy $90 \mathrm{~W}-\mathrm{Ni}$-fe, the hardness decreases with the increase in the sintering temperature for small powders (Faridakhtar, 2008 and Meilakh, 2009). Smaller micro and nanopowders are increasingly applied in powder metallurgy process due to their special characteristics (Chen et al., 1997 and Wang et al., 2003). Particles with diameter of less than 100 nanometer, in comparison with the bigger particles have higher surface to volume ratio which initiates different characteristics (Chio et al., 2002). These new characteristics such as high surface area result in the intense decrease in sintering temperature, severe viscidity, and unique erosion resistance and favorable mechanical features (Chio et al., 2002). Powder size is so influential on dimension variation during sintering. For smaller powders more compaction happens in a 
certain sintering time. Furthermore the speed of compaction for smaller powders is remarkably faster than that for bigger powders (Cheney et al., 1965). Moreover, the effect of particle's size, on the time and temperature of the sintering of the composite pieces, $\mathrm{AL}-\mathrm{AL}_{2} \mathrm{O}_{3}$, is surveyed. The results indicate that when the size of the particle decreases, both product hardness and strength increase. In addition, the highest hardness is achieved in the pieces made with smaller particles and the moderate keeping time and temperatures. An Increase in time and temperature results in a decrease in hardness and strength which could be due to the particles' growth (Rahimian, 2009). Researches on nanopowder sintering using SPS process show that needed sintering temperature for Nan powder is 200-500 degree less than that for normal size powders (Angerer et al., 2005). With increase in density and increase in compacting pressure and sintering time and temperature, mechanical properties like tensile strength and elongation improves. With increase in sintering time, mostly there is no change in strength and density even though toughness of the product increases. When lubricant is added to the raw powder, density decreases linearly (Libsch et al., 1970 and Babakhani et al., 2006). Koch reported that when powder size decreases, flexibility increases and it seems nanopowder can increase flexibility of the product (Koch et al., 1999 and Koch, 2003). applying higher pressure number of contacting points increases, thus load carrying capacity of the work piece increases too (Chin et al., 2005). In this paper the effect of process parameters on the product density and consequently on product tensile strength is investigated. Powder size, keeping time, pressure and sintering temperatures are considered as the most influential parameters in powder metallurgy.

\section{Material properties and research method}

In this research, the powder metallurgy operation using the iron powder with 99.7 purity and size of 5,45 and 63 microns with additional $20 \%$ of nanopowder to the set with 45 micron iron and also mere iron nanopowder are performed. Iron nanopowder is produced using the planet miller; Fritsch P-6, in which bullets and container are made of high strength steel. In this research, bullet/powder weight proportion (BPR) of 10:1, milling time of 27 hours, and the miller rotation speed of $600 \mathrm{rpm}$ are used for milling. Alcohol is used to dilute the process (Suryanarayana, 2005). Figure 1 shows scanned electron microscope (SEM) picture of the product cross section. Characteristics of the part produced by powders with the average size of $80 \mathrm{~nm}$ are listed in the Table 1. Powder of zinc STEARAT with low melting point and approximate density of $1.09 \mathrm{~g} / \mathrm{cm}^{3}$ is used as lubricant in the powder mixture. The effect of frame wall lubrication was also investigated.

Table 1. Characteristics of the used iron nanopowder

\begin{tabular}{|c|c|c|c|}
\hline $\begin{array}{c}\text { Bit size average } \\
(\mathrm{nm})\end{array}$ & $\begin{array}{c}\text { Allowed changes } \\
(\mathrm{nm})\end{array}$ & $\begin{array}{l}\text { Special surface area } \\
\frac{m^{2}}{g}\end{array}$ & $\begin{array}{l}\text { Volume density } \\
\left(\mathrm{g} / \mathrm{cm}^{3}\right)\end{array}$ \\
\hline 80 & $\geq 60 \sim 100$ & $>8$ & $0.06 \sim 0.8$ \\
\hline
\end{tabular}

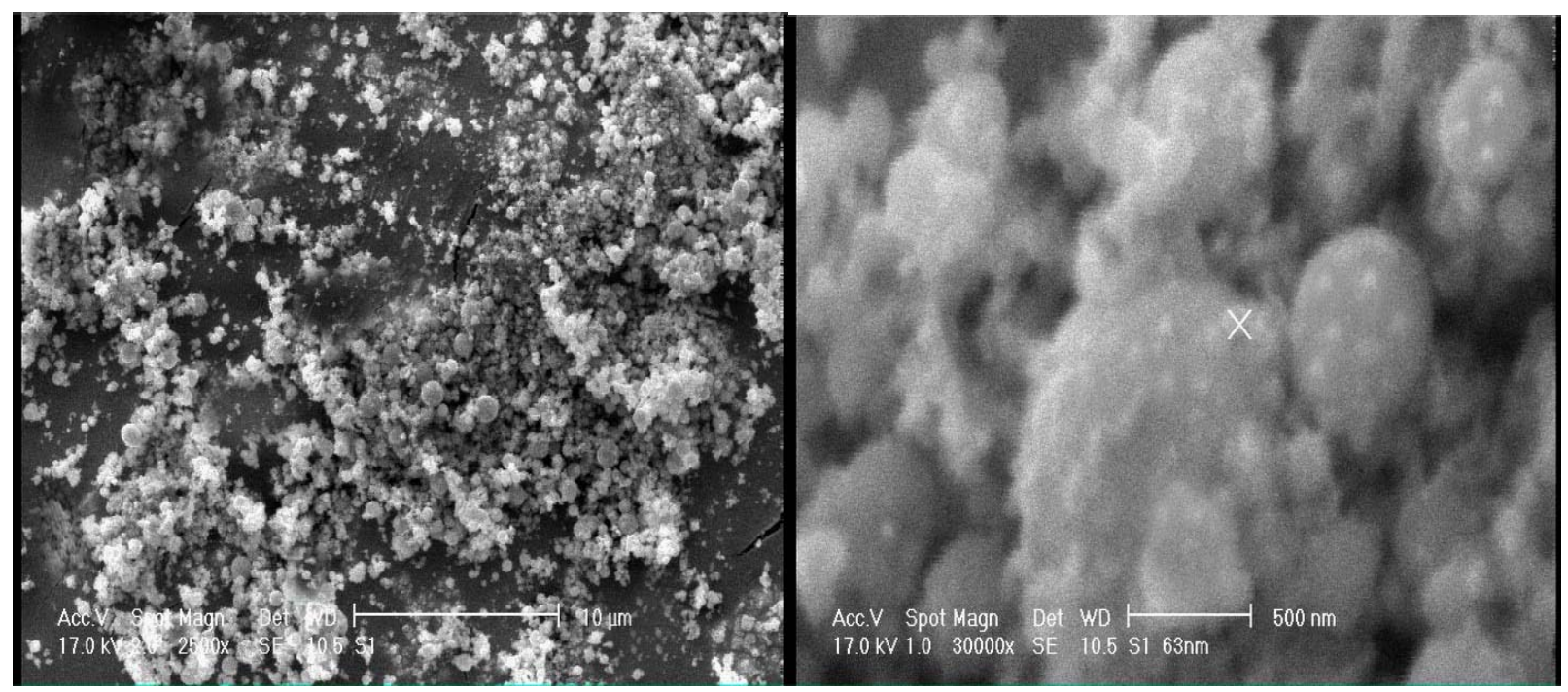

Figure 1. SEM picture from the produced iron nano powder

In Figure 2, PSA test was used for obtaining the average size of powder size. XRD pattern of nanopowder can be observed in Figure 3. As can be seen from figure $3 \mathrm{XRD}$ results reveal that there is no especial phase affecting samples. It is attributed to the 
high purity of the used Iron nanopowder in producing samples. Existence of few amounts of S and C which is detected by X-ray is intrinsic in used nanopowder.

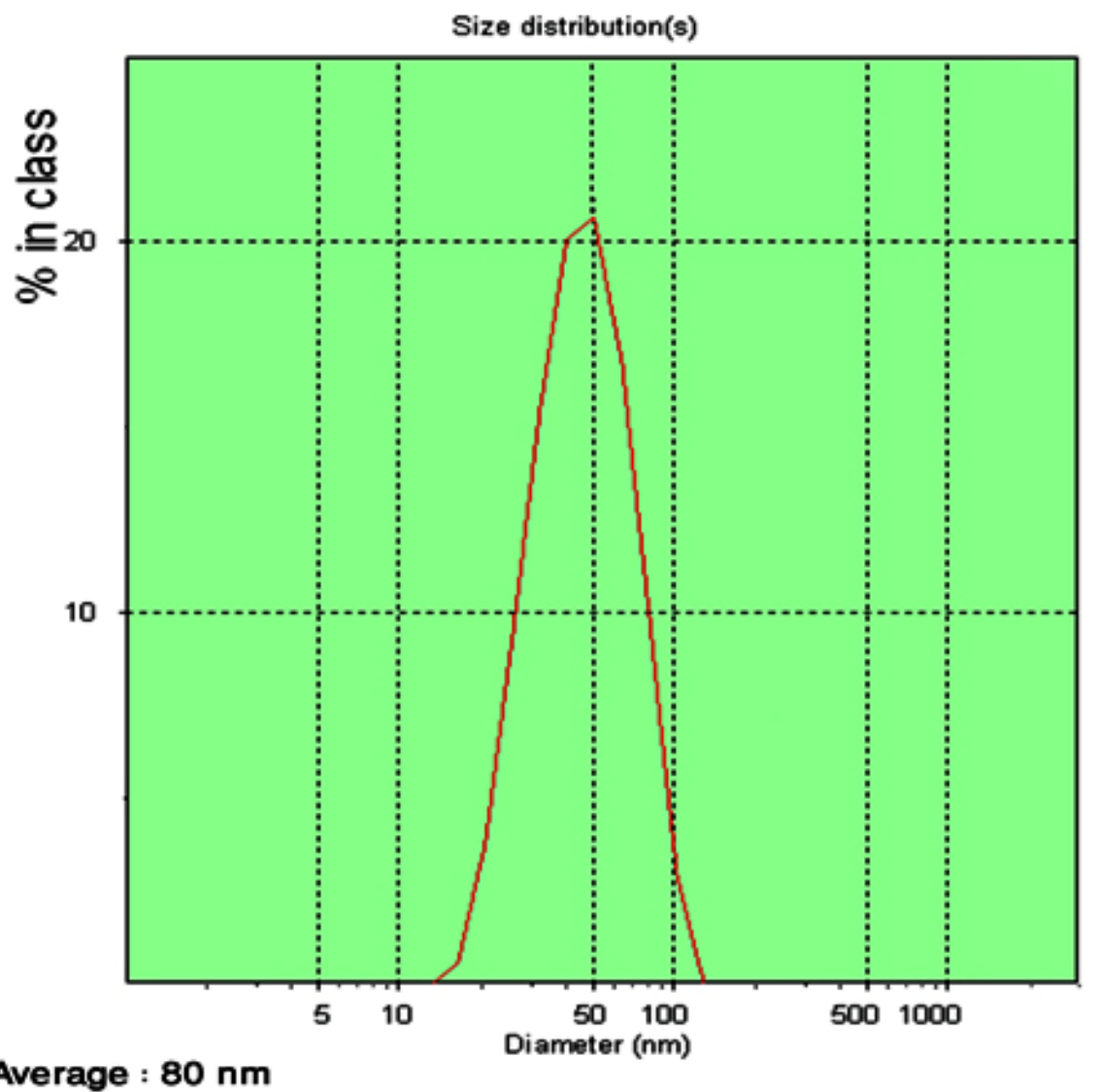

ZAverage : $80 \mathrm{~nm}$

Figure 2. Histogram test (PSA) for attaining the average size of Iron nano powder

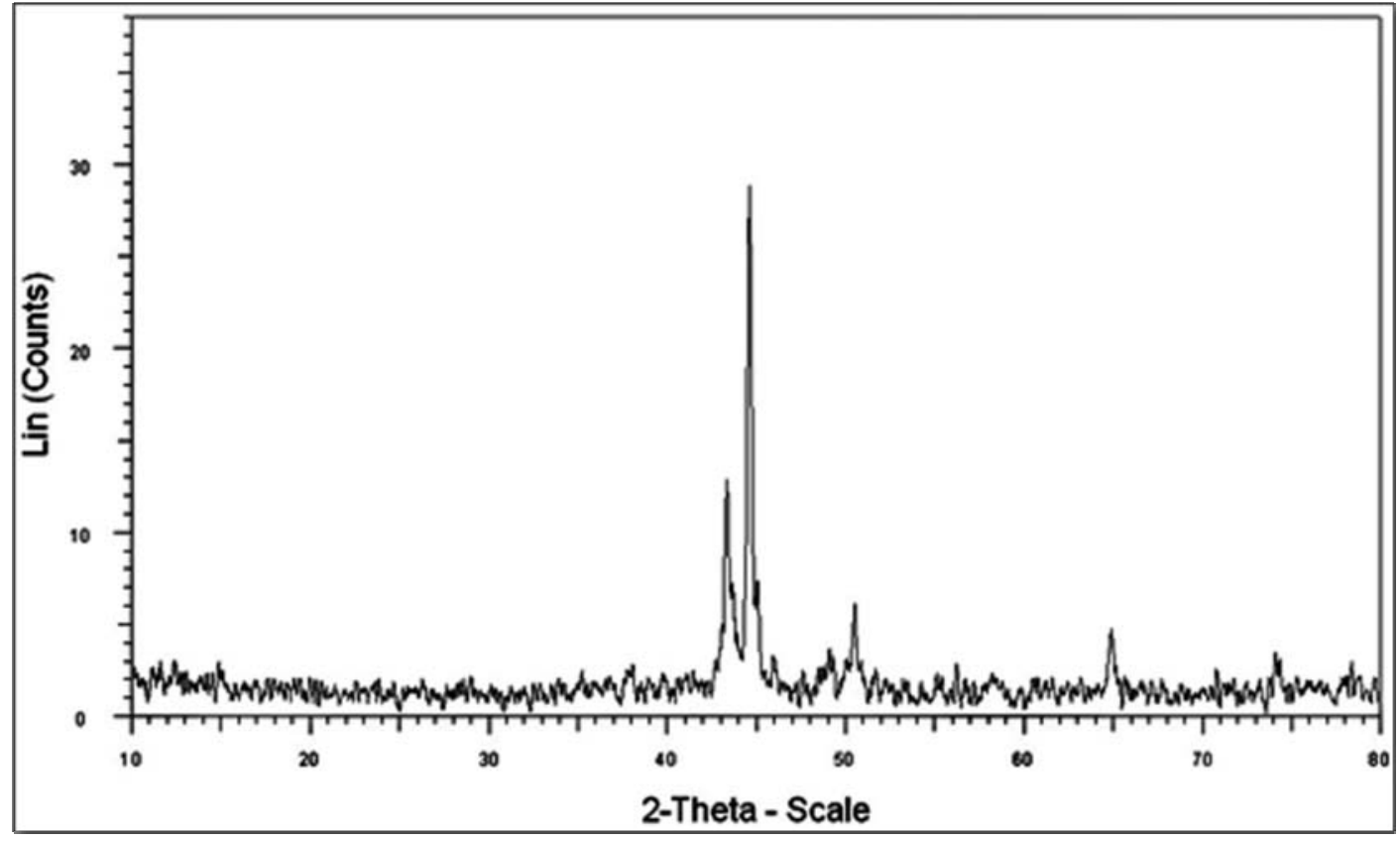

Figure 3. XRD pattern of the used nano-iron powder 
Tensile test samples are compacted in the setting temperature and various pressures based on ASTM E8 standard (Figure 4).

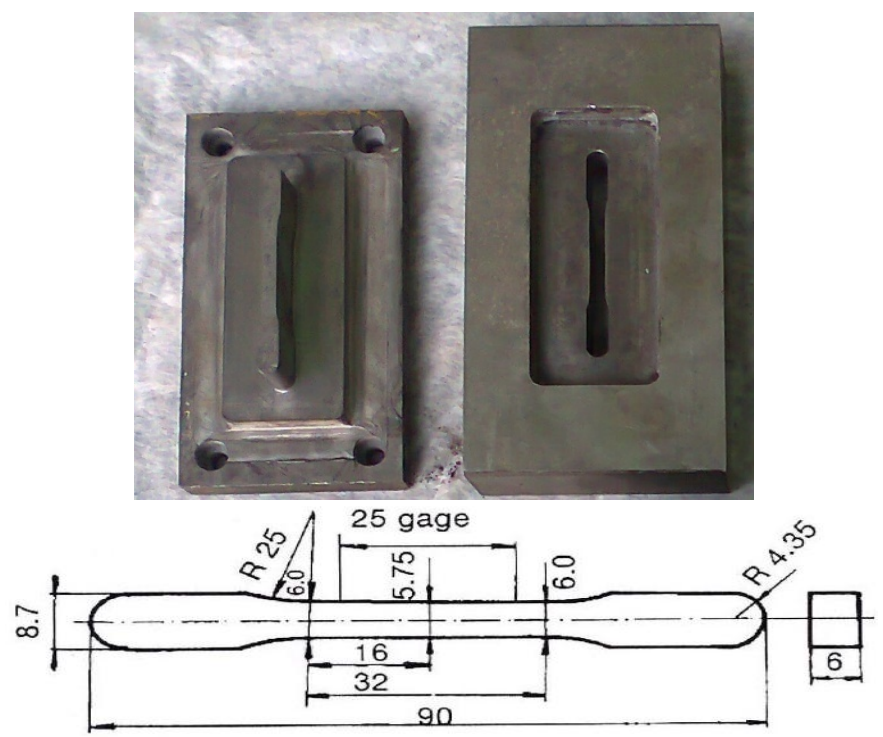

Figure 4. Tensile test sample and die setting based on ASTM E8

After compacting, the pieces were sintered using different keeping times and temperatures in a 4 torr vacuum oven, TAV, with the cooling atmosphere of nitrogen gas. The density of the raw sample was determined using geometrical method and the density of the sintered samples is determined according to ASTM B311 based on Archimedes principle. for each experimental set, tensile strength is determined by 25 ton pulling machine, Zwick / Roell Z050.

\section{Effects of process parameters on material properties}

As stated before, characteristics of the product are directly affected by the process parameters such as sintering temperature, keeping time, piece's density, and powder size. Here, the effect of powder size reduction and process parameters on the strength of the produced samples is investigated by experiments. 50 samples produced using different powder size, sintering temperature, pressure and keeping time are used in experiments. Parameters used in fabrication of some of the samples are in listed Table 2. Based on presented literature review it can be inferred that when the powder size decreases, more pressure and lubricant percentage are needed. Based on the data reported by Squire (1947), Chio et al. (2002), Koch et al. (1999) and Koch (1999), certain rang of pressure was chosen as compacting pressure producing products with raw density shown in Table 2 . Sintering time and temperature seem to decrease with powder size (Libsch et al., 1970 and Malow et al., 1998 and Kim et al., 2010). According to available data suitable range of sintering temperatures leading to a robust product with high strength were elicited and shown in Table 2 .

Table2. Process parameters used in tensile test samples fabrication and tensile strength and sample density results

\begin{tabular}{|c|c|c|c|c|c|c|c|}
\hline $\begin{array}{l}\text { Size of } \\
\text { iron } \\
\text { powder }\end{array}$ & $\begin{array}{l}\text { Lubrication } \\
\text { in mixture }\end{array}$ & $\begin{array}{l}\text { Pressure } \\
(\mathrm{MPa})\end{array}$ & $\begin{array}{l}\text { Raw } \\
\text { density }\end{array}$ & $\begin{array}{l}\text { Sinter } \\
\text { temperature }\end{array}$ & $\begin{array}{l}\text { keeping } \\
\text { time }(\min )\end{array}$ & $\begin{array}{l}\text { Density } \\
\text { After } \\
\text { Sintering }\end{array}$ & $\begin{array}{l}\text { Tensile } \\
\text { Strength } \\
(\mathrm{MPa})\end{array}$ \\
\hline $63 \mu \mathrm{m}$ & 0.6 & 500 & 6.8 & 1120 & 30 & 6.82 & 456 \\
\hline $63 \mu \mathrm{m}$ & 0.6 & 500 & 6.8 & 900 & 30 & 6.84 & 494 \\
\hline $63 \mu \mathrm{m}$ & 0.6 & 500 & 6.8 & 750 & 30 & 6.83 & 481 \\
\hline $63 \mu \mathrm{m}$ & 0.6 & 400 & 6.4 & 900 & 30 & 6.44 & 483 \\
\hline $63 \mu \mathrm{m}$ & None & 500 & 7.15 & 900 & 30 & 7.19 & 500 \\
\hline $45 \mu \mathrm{m}$ & 0.6 & 500 & 6.65 & 900 & 30 & 6.7 & 498 \\
\hline $45 \mu \mathrm{m}$ & 0.6 & 450 & 6.5 & 900 & 20 & 6.54 & 483 \\
\hline $45 \mu \mathrm{m}$ & 0.6 & 500 & 6.65 & 1120 & 20 & 6.68 & 458 \\
\hline $45 \mu \mathrm{m}$ & None & 550 & 7.06 & 900 & 30 & 7.12 & 515 \\
\hline $45 \mu \mathrm{m}$ & None & 500 & 6.95 & 900 & 30 & 7 & 511 \\
\hline $5 \mu \mathrm{m}$ & 0.6 & 600 & 6.45 & 900 & 20 & 6.51 & 494 \\
\hline $5 \mu \mathrm{m}$ & 0.6 & 650 & 6.6 & 900 & 30 & 6.69 & 507 \\
\hline
\end{tabular}




\begin{tabular}{|l|l|l|l|l|l|l|l|}
\hline $5 \mu \mathrm{m}$ & 0.6 & 650 & 6.6 & 750 & 30 & 6.67 & 496 \\
\hline $5 \mu \mathrm{m}$ & None & 700 & 7.1 & 900 & 30 & 7.18 & 521 \\
\hline $\begin{array}{l}45 \mu \mathrm{m} \text { with } \\
20 \% \text { nano }\end{array}$ & None & 700 & 7.25 & 900 & 20 & 7.30 & 523 \\
\hline $\begin{array}{l}45 \mu \mathrm{m} \text { with } \\
20 \% \text { nano }\end{array}$ & None & 700 & 7.25 & 750 & 30 & 7.29 & 517 \\
\hline $80 \mathrm{Nm}$ & 0.4 & 800 & 6.9 & 750 & 30 & 7.02 & 473 \\
\hline $80 \mathrm{Nm}$ & 0.4 & 800 & 6.9 & 600 & 30 & 7.04 & 495 \\
\hline $80 \mathrm{Nm}$ & 0.4 & 800 & 6.9 & 500 & 30 & 6.99 & 456 \\
\hline $80 \mathrm{Nm}$ & None & 850 & 7.06 & 600 & 30 & 7.13 & 504 \\
\hline
\end{tabular}

\section{Results and discussion}

\subsection{Lubrication}

Experimental results show that samples produced without using any lubrication yields higher tensile strength. Figure 5 shows that with the use of lubricants in different powder size, raw density decreases. this is attributed to low density of lubricant; adding lubricant decreases the whole density of raw sample.

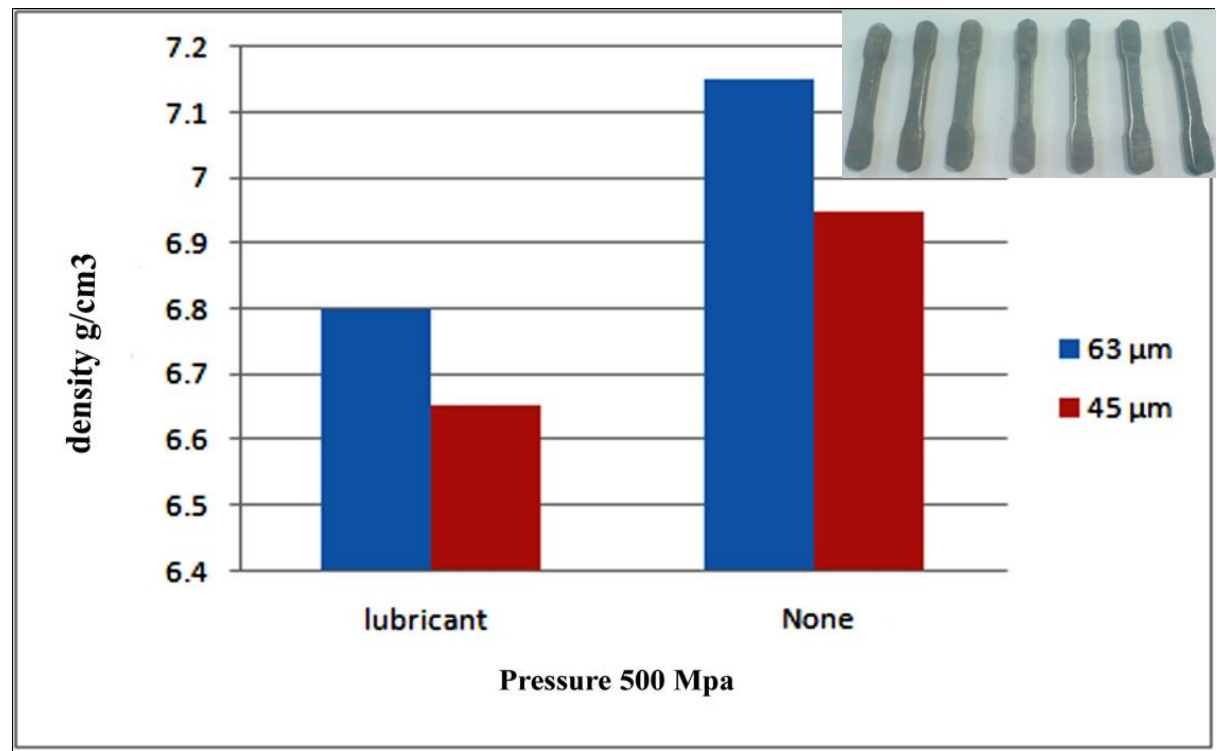

Figure 5. Effect of lubricant percentage on the strength of the compacted pieces

\subsection{Compaction}

As it can be observed from Table 2, the highest raw density in compacted pieces is obtained in higher pressures. Increase in density is explicable by increase in pressure, since it increases the number of contact points in powder bits. In nanopowders primary contact points before sintering increase with pressure and consequently uniform distribution of cavity can be obtained after sintering. Therefore the condition to attain the higher final density is available and consequently necessary sintering time decreases. Moreover, according to Fig6, for the nanopowder with no lubricant at the pressure of $850 \mathrm{MPa}$, raw density is 7.06 $\mathrm{g} / \mathrm{cm}^{3}$, while same density is obtained for $45 \mu \mathrm{m}$ powder at the pressure of $550 \mathrm{MPa}$. Furthermore for powder with the size of 63 micron in pressure of $500 \mathrm{MPa}$, raw density was $7.15 \mathrm{~g} / \mathrm{c} \mathrm{m}^{3}$ while in this pressure raw density was $6.95 \mathrm{~g} / \mathrm{c} \mathrm{m}^{3}$ for powder with the size of 45 micron. This phenomenon can be explained by the fact that when powder size decreases in a constant pressure, less raw density will be obtained, because smaller powders are harder to be compacted, and consequently sintered samples have less density and tensile strength. However this decrease in powder size brings an advantage in which less sintering time and temperature are needed. Figure 6 also shows that apart from powder size increase in pressure results increase in density. 

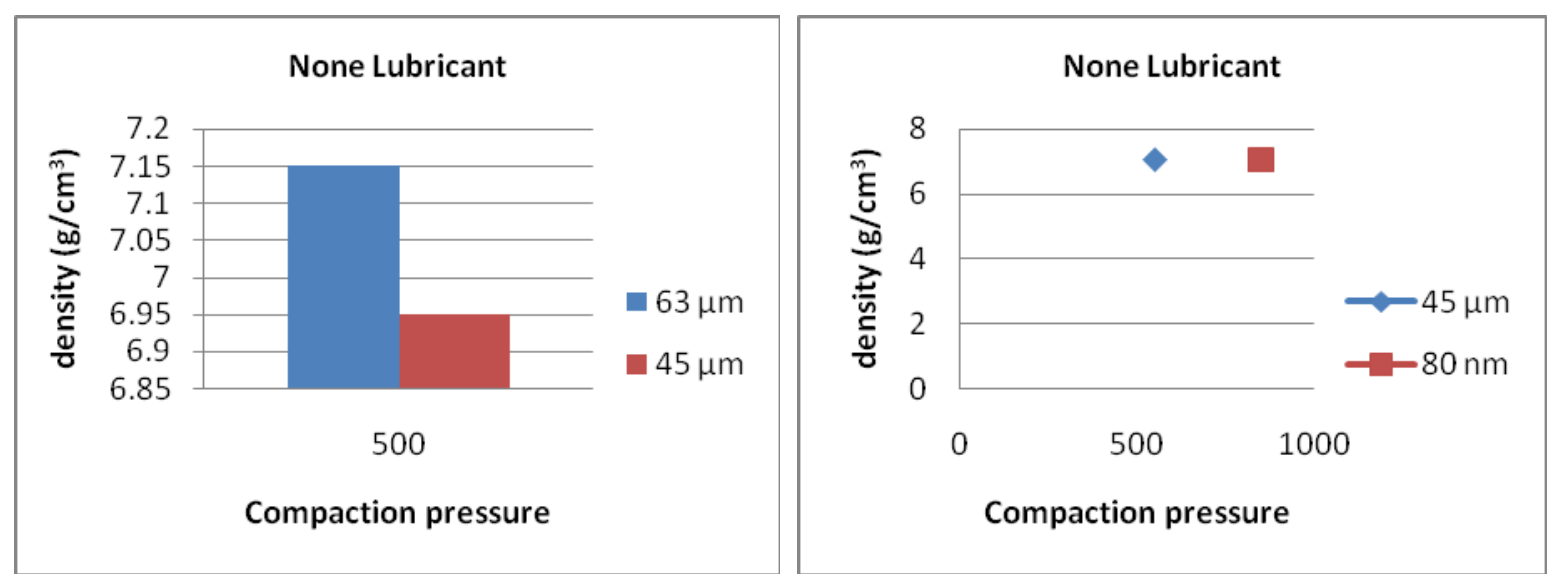

Figure6. Effect of compacting on the raw density for iron powder with various bit size

\subsection{Sintering time and temperature}

As stated before increase in temperature and keeping time raises the costs and makes the conditions of the production difficult. When the powder size decreases bits' surface /volume ratio increases. This increase, which is more observable in the Nano bits, increases sintering speed particularly in the first step of the sintering which is called the cols (defiles) establishment. Decrease in powder size also makes more atoms being involved in filling middle spaces which decreases the porosity and increases the hardness of the final product. It is worth to mention that powders which are made by mechanical alloy-making have higher sintering speed due to the spherical form of the bits.
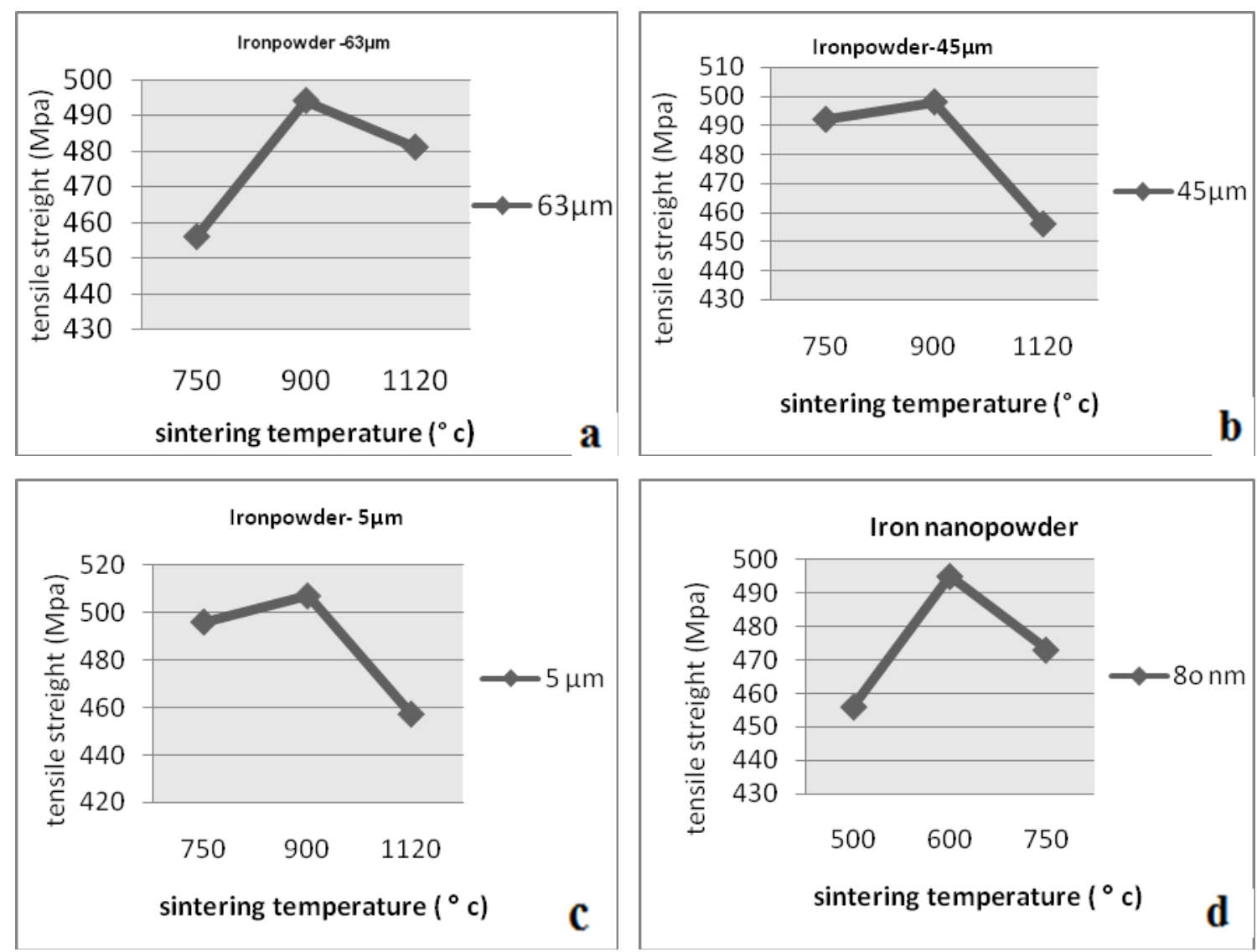

Figure7. Effect of various temperatures in the pieces sintered with close densities to each other and preservation time of 30 minutes in oven (a) iron powder 63 micron (b) iron powder 45 micron (c) iron powder 5 micron (d) iron Nanopowder with average size of 80 Nanometer. 
Figure 7 shows the effect of the powder size on optimized sintering temperature leading parts to show higher tensile strength. Based on figure 7 it can be seen that when the powder size decreases, the sintering can be carried out at lower temperatures. It is because of the intense sensitivity of the surface penetration to bit size reduction. High surface to volume ratios in small bits not only lowers the sintering temperature, which technologically has important advantages such as the possibility to omit sinterassisted, and to avoid unfavorable phase transformation but also it causes severe adhesion between the bits and consequently higher strength of the pieces.

Considering experimental results, increasing keeping time for samples with smaller bits especially in Nonopowders makes a plateau in tensile strength and highest strength is obtained at the medium keeping time. The main reason for hardness reduction with temperature can be explained by the opposite effect of density and bit size on samples' strength; although applying high pressure and powder made by mechanical miller, bit growth can be avoided.

Figure 8 depicts density changes with sintering temperature . Increase in the density of sintered samples compared to that of raw samples is due to the samples' powder shrinkage in the sintering process. This shrinkage is more in the smaller powders. In samples produced without lubricant, this increase in the density is more noticeable since by using lubricants, density of the samples decreases. it can be attributed to gases emerging from the evaporation of the lubricant in the sample.

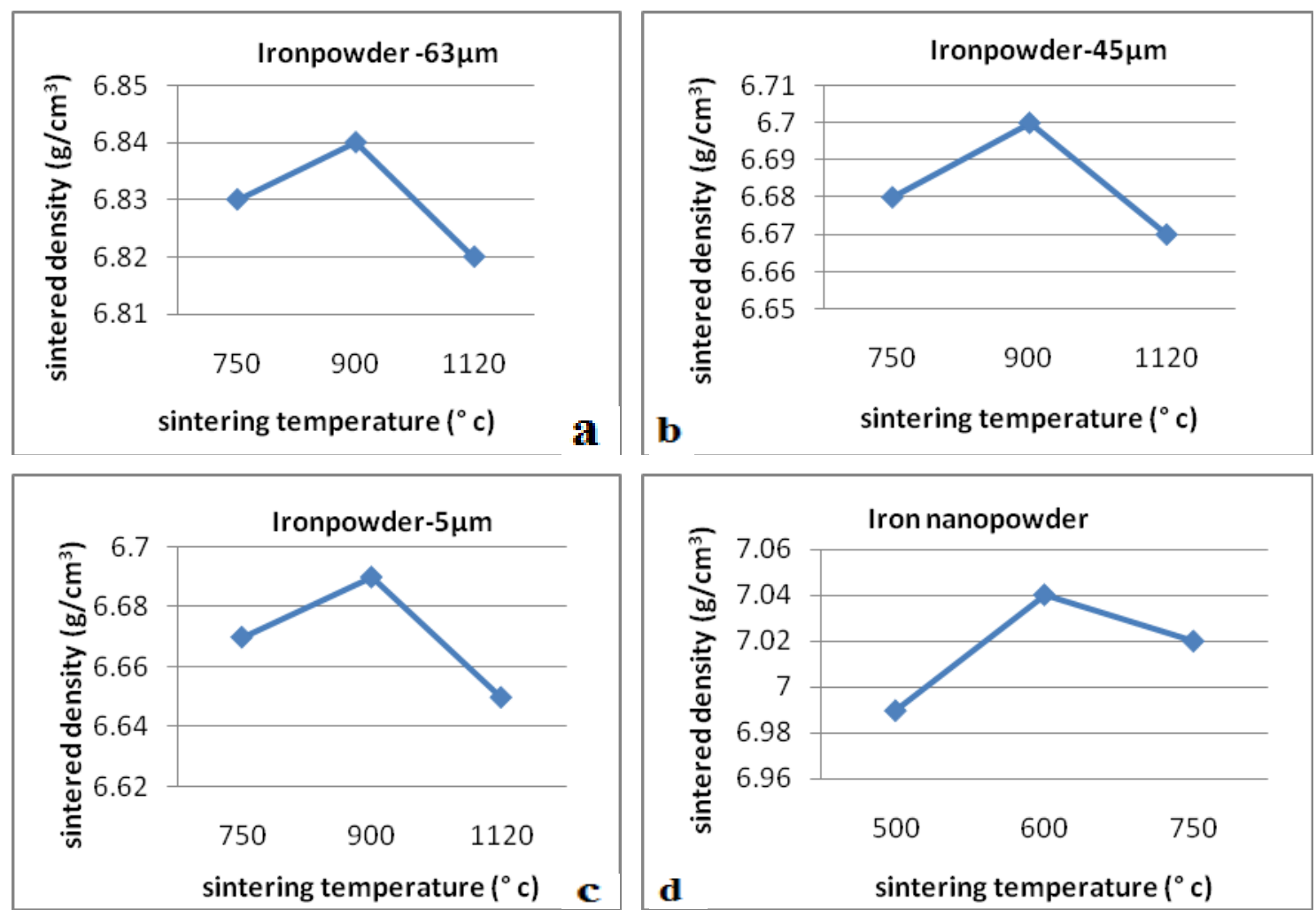

Figure 8. Effect of temperature on the density of the sintering samples (a) iron powder 63 micron (b) iron powder 45 micron (c) iron powder 5 micron (d) iron nanopowder with 80 nanometer average

As seen in Figure 8, the volume compression and the proportional density of the sintered materials in smaller powders have considerably increased. This shows the direct relation between samples' density and tensile strength. For nanopowder, higher pressures and relatively lower sintering temperature are necessary to obtain higher raw densities. More contact points of the 5 micron iron powders and particularly nanopowder makes more condensation in materials and subsequently increase in the tensile strength.

\subsection{Fracture section topography}

In Figure 9, SEM pictures of the fracture section for two samples are shown. Figure 9 (a) is taken from a samples with 63 micron powder size and the sintering temperature of $1120^{\circ} \mathrm{C}$ and 30 minutes keeping time. Figure $9(\mathrm{~b})$ is for the sample with 80 nanometer powder size at the $600^{\circ} \mathrm{C}$ and 30 minutes keeping time. 

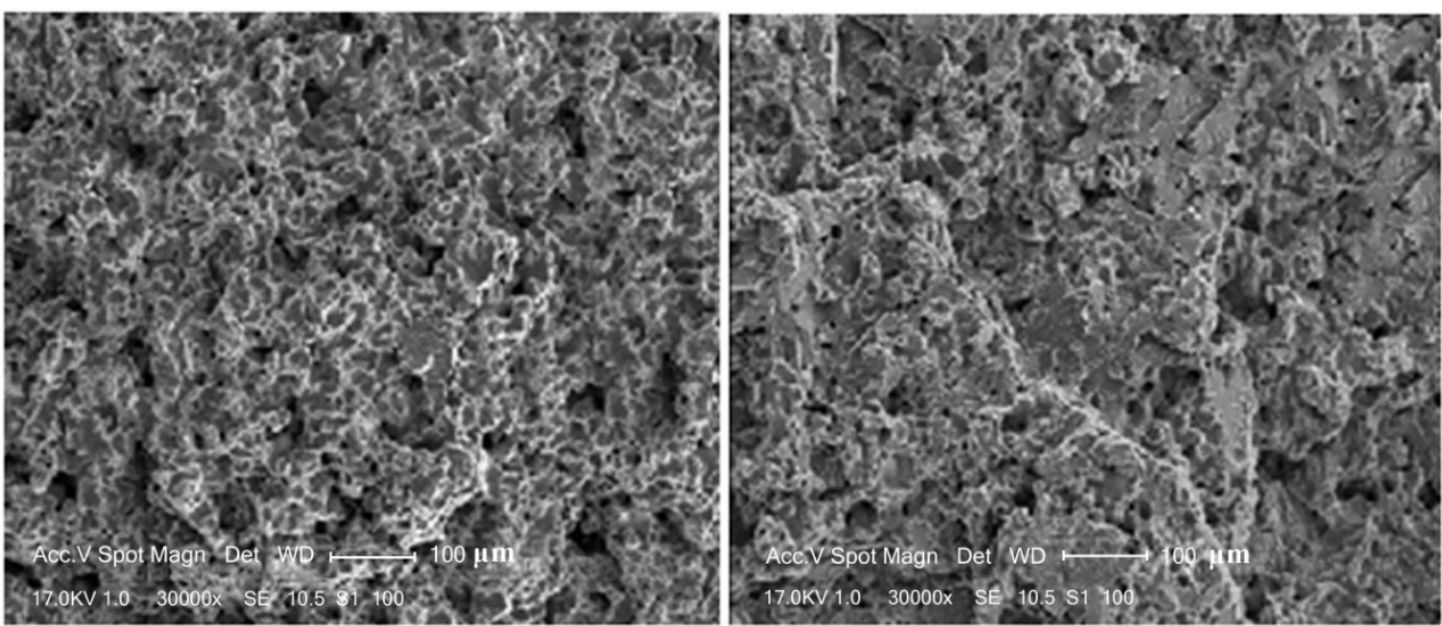

Figure 9. Surface of made samples (a) powder $63 \mu \mathrm{m}$ and sintering temperature $1120^{\circ} \mathrm{C}$

(b) powder $80 \mathrm{~nm}$ and sintering temperature $600^{\circ} \mathrm{C}$

As can be observed from table 2, $495 \mathrm{MPa}$ tensile strength of the nanopowder is obtained at less sintering temperature when it is compared with 63 micron powder size. It can be concluded that in addition to the complete sintering of the tiny powders at low temperatures, strength of the produced samples, as can be seen in the fig 9, increases due to the existence of high contact surface which speeds up transmission to the sintering bottle-necks. Therefore neck thickness increases and the porosity percentage decreases and consequently density increases and the strength of the pieces ascends significantly.

\section{Conclusion}

In this paper tensile strength of samples with different iron Micro-powder size of 63 m, 45 m, 5 m, 45 m and addition of 20 $\%$ of the nanopowder and also iron nanopowder with average size of $80 \mathrm{~nm}$ was investigated experimentally. the effect of process parameters such as sintering temperature, keeping time and compaction pressure on tensile strength was studied and followings results are obtained:

- Decrease in powder size in order to achieve a high raw density needs a very high pressure.

- As density goes up with compression, temperature and keeping time, mechanical characteristics and particularly tensile strength improves. in smaller powders, regarding high sensitivity of surface diffusion mechanisms to the bit size and increase in sintering activation energy, higher density is established at lower temperatures and medium keeping times;

- With decrease in necessary sintering temperature need of sinter-assisted materials can be neglected and the sintering costs are decreased.

- The strength of samples made by smaller powders is higher because they need higher compaction pressure which decreases samples' porosity.

- The powder size has intense effect on the dimensional changes in sintering. For a specified sintering time, more bits in smaller powders are accumulated and consequently accumulation speed for smaller powders is considerably faster.

- With increase in the percentage of the lubricant in the powder mixture, the samples' raw density decreases.

\section{References}

Angerer P., Yu L.G., Khor K.A., Korb G. and Zalite I.. 2005. Spark-plasma-sintering (SPS) of nanostructured titanium carbonitride powders. J. European Ceramic Society, Vol. 25, p. 1919.

Babakhani A., Gambari M., Haerian A. 2006. Investigation of the effect of lubricant and compaction temperature on mechanical properties of warm compacted p/m parts, Sci Eng A, Vol. 652, p. 36.

Chen Y., Glumac N., Kear B.H., Skandan G. 1997. High rate synthesis of nanophase materials. Nanostruct.Mater. Vol. 9

Cheney R. F., Sylvania G. T. E., Towanda, P. A, 1965. Lecture on sintering of tungsten and molybdenum,Oct.

Chin P. P., Ding J., Yi J. B. and Liu B. H., 2005. Synthesis of $\mathrm{FeS}_{2}$ and FeS nanoparticle by high-energy mechanical milling and mechanochemical processing, Journal of Alloys and Compounds, Vol. 390, pp. 225-260.

Chio C.J., Tolochko O., Kim B.K.. 2002. Preparation of iron nanoparticles by chemical vapor condensation. Mater. Lett. Vol. 56, p. 289. 
Faridakhtar, 2008. An investigation on the solid state sintering of mechanically alloyed nano-structured $90 \mathrm{~W}-\mathrm{Ni}-\mathrm{Fe}$ Tungsten heavy alloy, International Journal of Refractory Metal \& Hard Materials, Vol. 26, pp. 145-151.

Fillabi M. G. and Simchi A. and Kokabi A. H., 2008. Effect of iron particle size on the diffusion to wrought carbon steels, Materials and Design Vol. 29, pp. 411-417.

Kim K.H., Lee B.-T., Choi C.-J., 2010. Fabrication and evaluation of powder injection molded Fi-Ni sintered bodies using nano Fe-50\%Ni powder, Journal of Alloys and compounds, Vol. 491, pp. 391-394.

Koch C.C., 1999. Nanostructure Science and Technology, NSTC Report Worldwide Status and Trends, Kluwer Academic Publ., Dordrecht, the Netherlands, Vol. 93.

Koch C.C., Morris D.G., Lu K., Inoue A., 1999. Ductility of nanostructured materials. MRS Bull, Vol. 24, p.54

Koch CC. 2003. Ductility in nanostructured and ultra fine-grained materials: recent evidence for optimism, Nanocryst Mater, Vol. 18 , p. 9.

Libsch J., Volterra R. and Wulff J. 1970. The sintering of iron powder, Powder Metallurgy, ed. by Wulff J., Cleveland, p. 379394.

Malow T.R., Koch C.C., Miraglia O.Q.W., Murty KL. 1998. Compressive mechanical behavior of nanocrystalline Fe investigated with an automated ball indentation technique. Mater Sci Eng A, Vol. 252, p. 36.

Meilakh A. G., 2009. Acceleration of iron-powder sintering by nanoparticles, Steel in Translation, Vol. 39, No. 1, pp. 81-83.

Park W. Y., Youn C.S., Oh Y.W., Choi C.J., 2004. Characteristics of Fe nanopowders synthesized by plasma arc discharge process. Korean J. Mater. Res. Vol. 14, No. 1.

Rahimian M., 2009. The effect of particle size, sintering temperature and sintering time on the properties of $\mathrm{AL}_{-} \mathrm{Al}_{2} \mathrm{O}_{3}$ composites, made by powder metallurgy, Journal of Materials Processing Technology, Vol. 209, pp. 5387-5393.

Squire A., 1947. Density relationship of iron-powder compacts, Trans. AIME, Vol. 171, pp. 485-503.

Suryanarayana C., 2001. Mechanical Alloying and Milling, Vol. 46.

Thomson G. 2003. Introduction to Nanotechnology, John Wiley \& Sons, Inc. NY. USA

Yang H., Atang, Zhang X., Yang W. and Quiu G.. 2004. $\mathrm{In}_{2} \mathrm{O}_{3}$ nanoparticles synthesized by mechanochemical processing. Scripta Materialia, Vol. 50, pp. 413-415.

Wang Z. H., Choi C.J., Kim B.K., Zhang Z.D. 2003. Characterisation of Fe-Co alloyed nanoparticles synthesized by chemical vapor condensation. Mater. Lett. Vol. 57, p. 3560.

\section{Biographical notes}

M. Delavari graduated in Mechanical Engineering from Iran University of Science and Technology (IUST), Iran in 2008 and received his Master Degree in Mechanical Engineering (Manufacturing) from School of Engineering and Hi-tech, Iran University of Industries and Mines in 2011. He is presently working on mechanical alloying process and produce of metal nano powders.

A. Salarvand is a graduated researcher in department of Mechanical engineering at Doroud Azad University. He is presently worked on manufacturing process control and simulation

A. Rahi is currently an Assistant Professor in School of Engineering and Hi-tech, Iran University of Industries and Mines (IUIM). He graduated in Mechanical Engineering from Isfahan University of Technology, Iran in 1993. He received his Masters Degree and PhD from Amirkabir University of Technology, Iran in 1995 and 2003, respectively. He has published over 35 research journals and conference proceedings.

F. Shahri is currently an Assistant Professor in School of Engineering and Hi-tech, Iran University of Industries and Mines (IUIM). He graduated in Material Engineering from Iran University of Science and Technology (IUST), Iran in 1994. He received his Masters Degree and PhD from Iran University of Science and Technology (IUST), in 1996 and 2004, respectively. He is presently working on metal nanopowders and mechanical alloying process.

Received December 2011

Accepted March 2012

Final acceptance in revised form August 2012 